\title{
Measuring Legacy: Architectural representation and cultural identity in an historical marker
}

\author{
Ian Aik-Soon Ng \\ University College of Technology Sarawak \\ Persiaran Brooke, 96000 Sibu, Sarawak, Malaysia \\ asng21@gmail.com
}

\begin{abstract}
This paper addresses the problem of adaptation and integration in relation to an immigrant culture by using an heritage building that possesses more than a passing historical significance to argue that sustaining an architectural work in the wake of vacillating subscription to its original use can be crucial to keeping alive contestations for community recognition. Beginning with an architect's gaze initiated by a measured drawing exercise, it observes a range of architectural adaptations that the building has undergone in integrating itself into a transposed location, before suggesting that consideration of the historical and social narratives embedded in building-and-builder is inevitable to map their communal contribution to national conversations fully. Employing a hybrid methodology of architectural case study and interpretive, literaturebased, social analysis, it finds that engagement with the equatorial climate wrought the most change to the northern Chinese typology of this building, and that there is a metaphorical parallel in the inherent narrative that highlights cultural negotiation and compromise. It concludes by arguing that any unequivocal quest for historical truth can only be healthy for a multicultural society that keeps vigil over political harmony, and that the process necessarily involves "re-storying" as much as "archaeological" findings. It suggests five potential areas for further research.
\end{abstract}

Keywords: architectural representation, cultural heritage, interpretive history, measured drawing, re-storying, Yap Ah Loy

${ }^{I}$ The contribution and reputation of these four leaders are shining bright!

${ }^{2}$ This land, in the past, was barren under the scorching sun; (i)n the remote areas, there were native tribes fighting fiercely.

${ }^{3}$ Upon arrival here, these leaders were determined to bring peace; (t)hey worked in succession, boosting industries and trade; (a)s the land became better developed, the people could enjoy good lives.

${ }^{4}$ The leaders also had long-term planning for building this country, (h)oping that the people could transcend territorial barriers to live together. 
${ }^{5}$ Believing that a temple was the most suitable venue for this purpose, Yap Ah Loy mooted the idea and donated a piece of land, (w)hile three other leaders endeavoured to plan and implement the work.

${ }^{6}$ The completed temple, beautiful and magnificent, (a)lso worships past heroes for their righteous and courageous deeds.

${ }^{7}$ To commemorate the leaders' noble deeds which have farreaching impact, (w)e thus set up this memorial plague for all to pay boundless respect. (Verse numbers and parentheses mine.)

Sin Sze Si Ya Temple Committee, 2009

\section{Introduction}

This paper discusses cultural heritage conveyed through the medium of architectural representation and through interpretive readings of history. I pursue the argument that interpreting the historical import of the originator of a building and the architecture of the building itself as a fusion of heritage material results in a complex composite of meanings that has far greater axiological value than its stand-alone components: Semantics increase in combination. The premise of the argument is that historical buildings and personality narratives are social constructs: Once built and once lived they morph over time in response to the imaginings and agendas of ensuing stakeholders whose actions are, in turn, moderated by the evolving societies they exist in. I also submit that heritage can be constituted by (among other vehicles) the measured drawing as cultural representation and by critical discourse on the contribution of historical figures to the social present. Discordant though it may sound at first mention, the subjects of this paper are (i) the oldest temple in Kuala Lumpur (capital of Malaysia) with fine architectural qualities, and (ii) its builder, Yap Ah Loy (from China) the acknowledged "founder of Kuala Lumpur" (until 1980 when this status was disputed for the first time). The (partly contested) superlatives and the multicultural context which they are a part of make a joint reading of the temple and its builder tenable. The paper thus, in the main, starts by presenting measured drawings of the Sin Sze Si Ya Temple with analytical commentary; it then discusses the emergence of Yap Ah Loy as a figure of constructive contention; before concluding with a synthesis that suggests further areas of research.

\section{Literature Review}

While an heritage building can be studied through a variety of disciplines ranging from engineering to architecture and culture it is the socio-scientific that best facilitates the aim of this paper. The concept of "heritage as a social construction" (Graham, 2002, p. 1,003) both broadens the field of view of the material here presented as well as provides the cognitive glue needed to elicit from the subject a "thick description" (Geertz $\&$ Darnton, 2017). The subjective-interpretive approach taken is necessarily selective to make sense of, and be relevant to, current issues. Following Graham (2002), I am "concerned with meanings (rather) than material artefacts" for it is meanings that contribute cultural value. In tandem, as Graham asserts in citing Hall (1997), culture is 
"essentially concerned with the production and exchange of meaning and their real, practical effects". The idea of representation is strongly suggested as a means of conceptualising heritage: It is by the methods we use things and represent them that "we give them a meaning" (Hall, 1997, p. 3). This is perhaps a theoretical link admitting the proposition that two devices may be regarded as conveyors of meaning: First, the architectural measured drawing, and second, historical narratives.

The measured drawing continues to be a tool of communication for architects, they also serve educational practitioners and researchers, with some contending that the measured drawing is a thick description "since it is a dense visual analysis of the architects' accumulation of the prevailing building elements as well as reflection of their multisensory experiences of the architectural context" (Akboy, 2017, p. 43). While Geertz, the seminal ethnographer, worked primarily with text, Akboy argues that he "recognized other representation mediums as modes of thick description" and that "drawings, films, and museum displays correspond to ethnographic inquiries" (Akboy, 2017) and while texts are inscribed social discourse that convert the passing moment of the occurrence of an event into an inscription that can be re-consulted (Geertz, 2017), the measured drawing, in parallel, transposes "the built environment along with the socio-cultural issues of events, persons, and places into graphical representations (Akboy, 2017). For the fact that measured drawings can be re-consulted by third parties, they are, in a sense, knowledge-bearers. Additionally, they are digested knowledge, outcomes of interpretation and negotiation.

The issue of negotiation of truth has been continuously emphasized by researchers, particularly so when heritage is seen as political resource as much as it is cultural product and knowledge. Graham (2002) suggests that the key questions for navigating the debate are "(i) why a particular interpretation of heritage is promoted, (ii) whose interests are advanced or retarded, and (ii) in what kind of milieu was (the knowledge) conceived and communicated?" (parentheses and numbering mine). This is clearly understood in a paper on the perception of Yap Ah Loy by contending communities in the societal context (Carstens, 1988) which, to date, remains one of the most comprehensive and summative work on the subject. Notwithstanding that, contenders for the status the subject once held, by a reinterpretation of history, continue to emerge, the latest in a book suggesting an alternative founder (to the current, government sanctioned, Raja Abdullah) of Kuala Lumpur (Lubis, 2018). Peer reviewed literature on Lubis' proposition is scant - though needful - but his substantial document cannot be discounted. It is needful on account of the socio-political function of heritage: Referencing Lowenthal (1998, 2016) Graham posits that not only does transparency regarding traits of the past provide "familiarity and guidance, enrichment and escape" it also establishes "validation and legitimation". However disputable past events might have been, reflection on them is inescapable for it is intrinsic to constructions of individual and communal representations of identity.

The literature seems to back using the Sin Sze Si Ya temple and narratives of its builder - with all its present day controversies - as material for problematizing this paper with a question on interpretation: In what way can we reinterpret the meaning of a morphed heritage in the face of social reconstructions? 


\section{Methodology}

As qualitative research my methodology is subjective and interpretive and aligns itself with the post-war moments of research analysis following Denzin \& Lincoln (2018). Research questions are outcomes of literature review, and my methods comprise architectural observations and analyses from site visits, and scrutiny of photographic records, both of which are subject to my experience as a trained architect. The narration of biographical details and related discussion on contestations in socio-significance is an outcome of a literature review of books and academic journals and as news pieces (for which I would recommend circumspect reading) as well as temple inscriptions translated from Chinese.

In the summary of Yap Ah Loy's emergence in Malayan (and later Malaysian) consciousness, no claim is made of originality of primary material: I have merely used a reading of Carstens (1988) Middlebrook, Gullick, \& Gibson-Hill (1951) and Gullick $(1988,2000)$ for a re-storying - a method that is based on the premise that "in research, we are representing a story" through my "own lens, gaze, and perspective" (Kovach, 2018). I subject the slant of my prose, and the small addition it makes to the picturing of the subject, to scrutiny by others. The other, perhaps more important, purpose for including a recounting is my argument that the Sin Sze Si Ya Temple and Yap Ah Loy are narratively synonymous, and correlated assessments are inevitable to lift discussions beyond a dispassionate "building study".

\section{Findings}

\section{Context of Heritage}

What was a coconut patch belonging to Yap Ah Loy in 1873 has now turned into an urban city block that houses the Sin Sze Si Ya Temple (Fig 1). It is one of many blocks in this part of Old Kuala Lumpur, characterized by a mix of heritage buildings of similar scale as well as tall modern buildings which include some of the more iconic skyscrapers of 21st Century Kuala Lumpur. Within its own block the Sin Sze Si Ya shares its space with the six, double-storeyed shophouses bequeathed by Yap (Fig. 2) and a multi-storey office that is the Hong Leong Building (Fig. 3). Encircling the block are the major streets - Tun H.S. Lee on the east, Jalan Cheng Lock on the south, and an unnamed street (essentially a back lane) on the west. The odd mix of (i) high-density and high-rise office, (ii) low-rise shop, and (iii) religious building within an urban lot is one instance of the change that the temple (which came first) has had to adapt to, i.e. the fast paced development in the early 1980s when there was less consciousness and legislation on conservation of historic enclaves.

The Hong Leong tower fills its own legal lot within this block without building setbacks, and hence its northern wall forms the boundary wall of the temple ground. The shophouses, similarly, fill the entire space on three sides of the temple - to the extent of sharing party walls with it - leaving only one really appreciable face, or elevation, to the temple - its south-western. This elevation looks onto a skimpy, triangular, remaining unbuilt ground of the block for a forecourt.

In later years a single storied substation, labelled "TNB" in Fig. 1, would be built in the triangle, no doubt to supply at least the Hong Leong Building, and thus reducing the utility and dignity of the forecourt. Aggravating the matter further, as the temple was orientated on principles of feng shui, it ends up facing a back street servicing another 
building block. Prior to the construction of the obstructing building block, the space in front of the temple would have been quite acceptable in terms of visual openness. This is now not the case. Nevertheless, although not the most ideal for views and open ground ceremonies, the layout still fulfilled, and continues to fulfil, the need to be in harmony with the landscape in terms of geomancy.

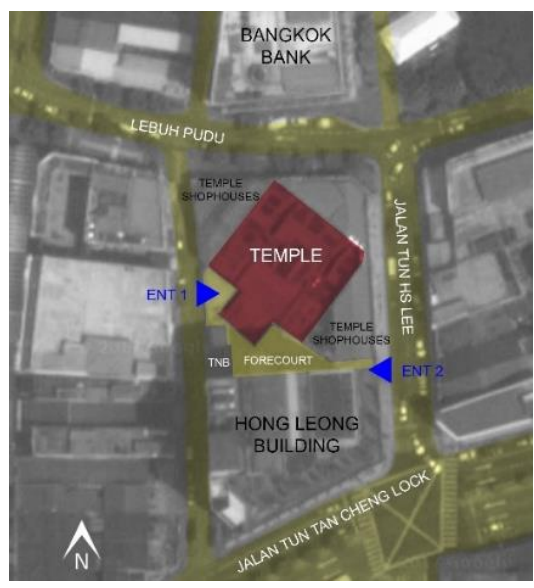

Figure 1. Site Plan of Temple (Source: Heffrence Teow, 2017)

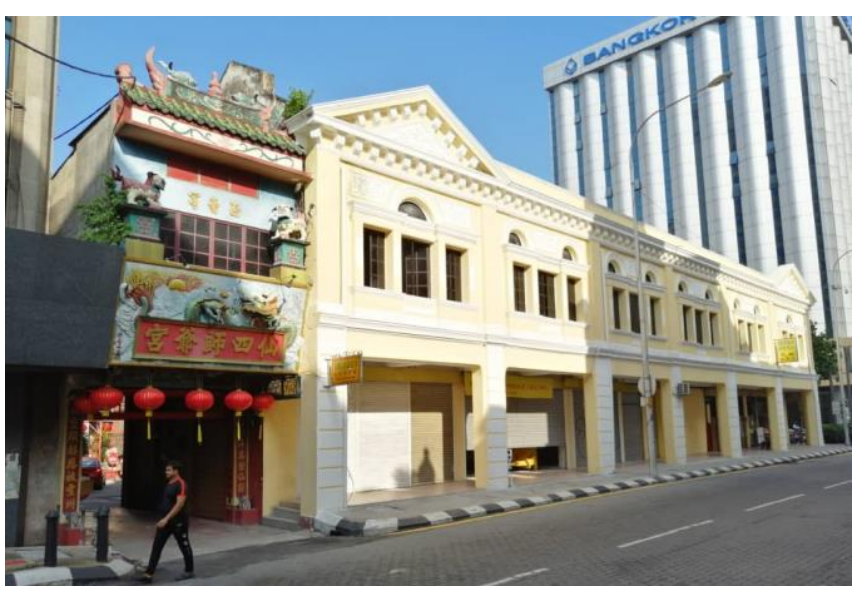

Figure 2. Yap's shophouses and Street presence of temple to Jalan Tun H.S. Lee. (Source: Author, 2019)

Ideally Taoists temples in towns and cities want a street presence, but in the case of the Sin Si Sze Ya the major thoroughfares are blocked off, and it unfortunately faces a back lane (Fig. 3). The solution to this was to create a street presence. On the side of Jalan Tun H.S. Lee (the major thoroughfare) an entrance tunnel that is the ground floor of one of the six shophouses was built, with traditional Chinese detailing, contrasting dramatically with the adjacent, period-styled facades and modern tower (Fig. 2). It contributes to the charm that is Kuala Lumpur - a mixture of architectural expressions in juxtaposition. Due to its modest presence on Jalan Tun H.S. Lee, relative to the scale of its neighbours, the temple - a building of considerable historical significance - is often missed by visitors, lost in the fabric of the city, resulting in a reputation of being a hidden gem.
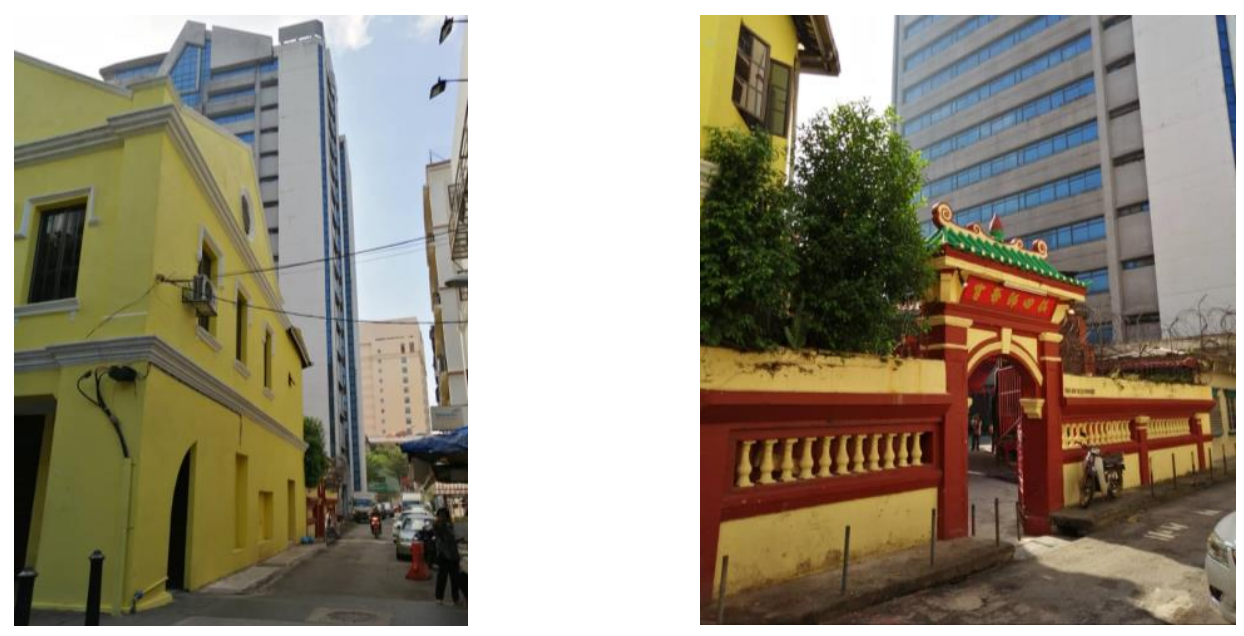

Figure 3. Back Lane presence, Hong Leong Building in background. (Source: Author, 2019) 
If secrecy leading to surprise were its planning strategy it could be concluded that the Sin Sze Si Ya has done well. The truth however is probably less flattering when one considers that most temples - being, at the least, community institutions and, at the most, expressions of honour to God - are positioned for maximum presence to public approach spaces. In its defence one may concede that Yap Ah Loy could not possibly have foreseen the ferociousness of commercial development ahead when he donated his coconut plantation to the Chinese mining community 144 years ago.

To fully understand the architecture of the Sin Si Sze Ya Temple, reference has to be made to generic, traditional courtyard house, one of the most basic organizations of form and space in Chinese architecture. Typically, the starting unit would comprise three sides of accommodation embracing a courtyard (Fig. 4, left).
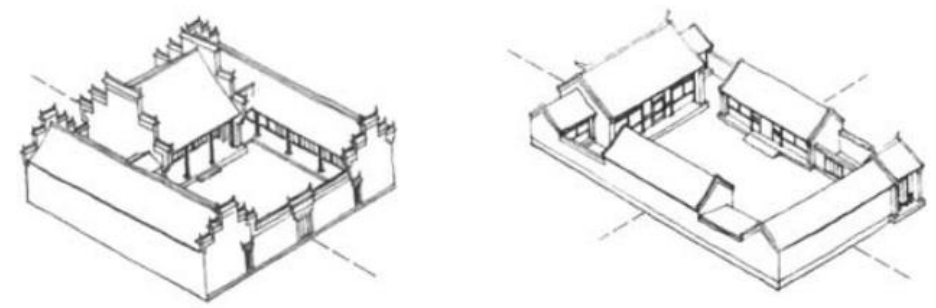

Figure 4. Typical three-sided (L) and four-sided (R) traditional Chinese courtyard house.

(Source: Author's adaptation from Liu Dunzhun, 2017)

An entrance wall with a door to the street would close off the fourth side to give privacy and protection. The main parent accommodation would occupy the central building whose architecture would correspondingly be of a more distinct scale and expression. Wing buildings would generally house bedrooms. A slightly more elaborate development of this genre would see the entrance wall replaced by the fourth accommodation block often relegated to servants (Fig. 4, right). It should be noted that the courtyard, as the name implies, would be a yard that is open to sky, a protected piece of the outdoors with the sun, rain and wind as natural elements that contribute to the substance and function of the household. It is usually as big on plan as the main house, often bigger. Overall the house is inward looking with no openings along the perimeter walls.

\section{An Architect's Gaze}

Yap Ah Loy had craftsmen-builders from China realize his temple. As an interpretation of the traditional courtyard house, or perhaps extracting from its architectural essence, one has to imagine that they conceptually compressed the foursided courtyard house to form a building with the vestige of an open courtyard. That the temple shared party walls with the shophouses on three sides was not compromise at all, but was in fact in alignment with traditional privacy principles. Thus to modern sensibilities the temple appears to be an infill in more than one sense: It is slotted into a square cut-out in a double-storey commercial volume (Fig. 1). The size of the square plan is virtually dictated by geomancy and the size of its city block as the approximately 45-degree rotation of the building in relation to the axis of the block meant that the temple could be no bigger. In my view, this is one illustration of design response to two things, (i) site (a non-geomantic city layout), and (ii) cultural context (geomancy). 


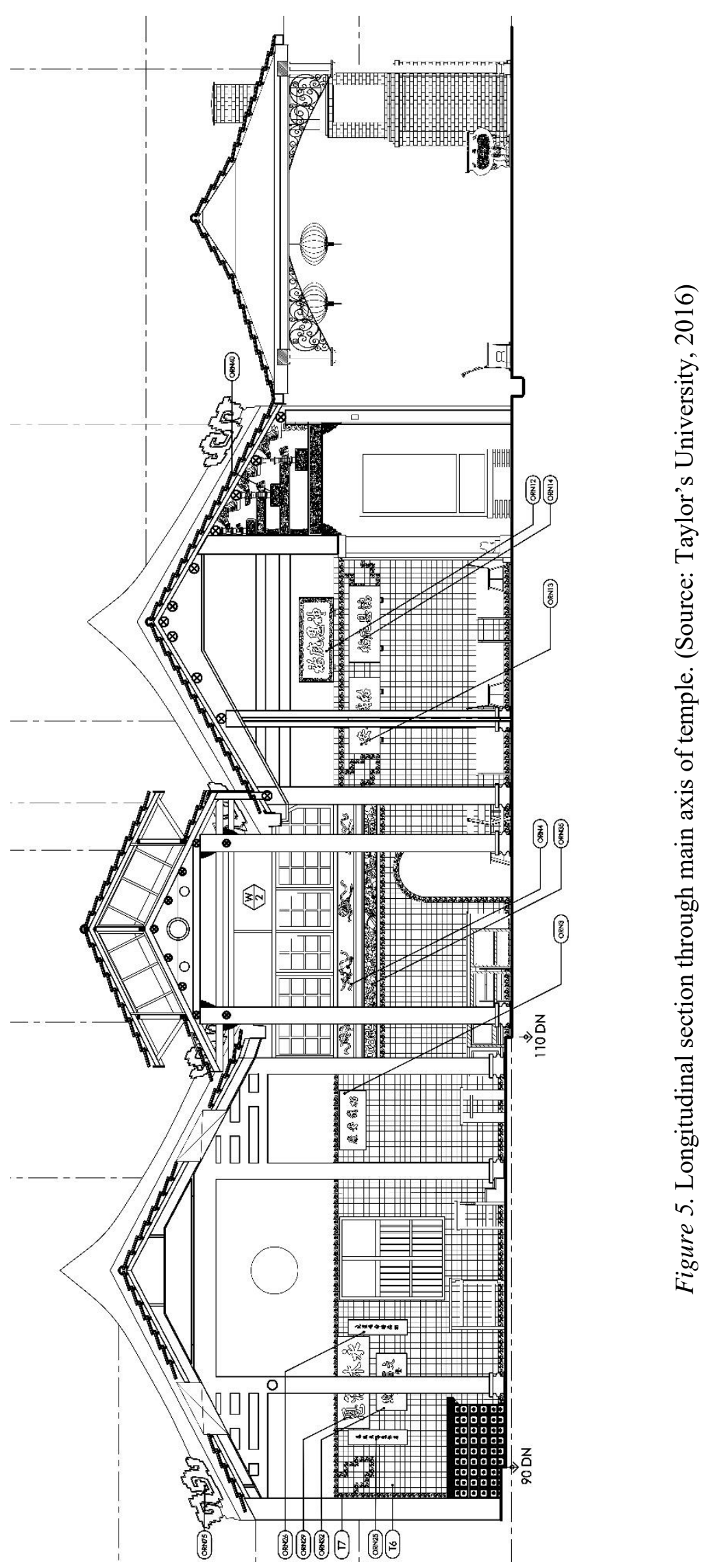


On walking through either of two entrances from the street, one is first accosted by a slight anomaly: There is a canopy of four, round-sectioned columns abutting the temple front (Fig. 5, at the right of the illustration). A hipped and pitched roof of concrete tiles is supported by these cast iron columns with filigreed corbels and mosaic tiled bases that are profiled to imitate traditional Chinese column bases. This structure can best be described as a porte cochere, indicating an adaptation to Western sensibilities (read British) as well as the tropical rainstorms indigenous to the locale.

The layout of the building is made plain by referring to the measured plan (Fig. 6). The square building consists of the Main Prayer Hall as the dominant space paralleling the "parents" room" - and the Main Entrance Lobby - the "entrance wing" Between these is the Inner Courtyard, and what is immediately clear is that the courtyard is no courtyard, being roofed over totally with transparent plastic and clad laterally with openable clerestory windows, approximating a sheltered atrium (Fig. 7).

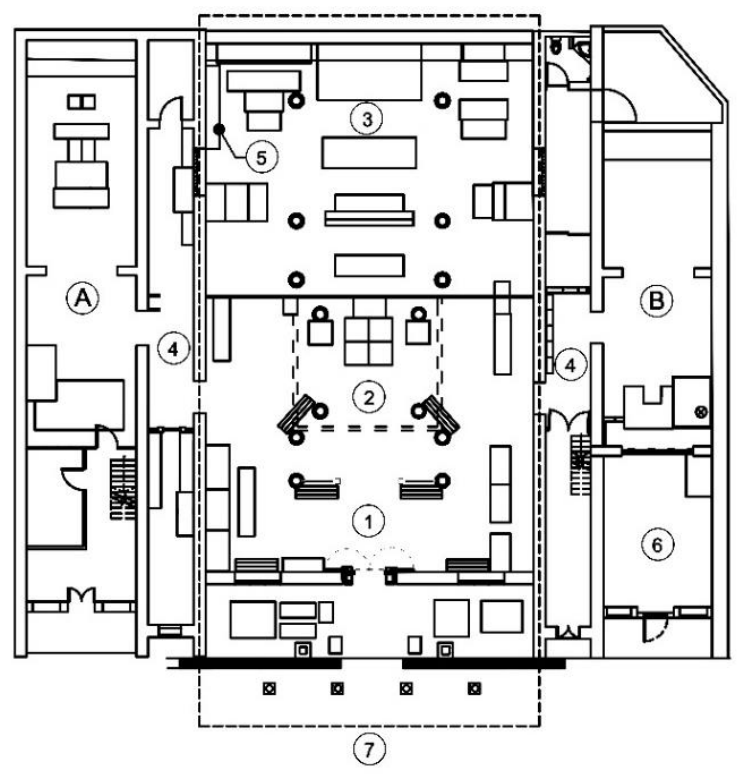

(A) ANCESTRAL HALL

(B) GUAN YIN HALL

(1) MAIN ENTRANCE FOYER

(2) INNER COURTYARD

(3) MAIN PRAYER HALL

(4) SERVICE SPACE

(5) PIONEERS OF THE TEMPLE

(6) COMMITTEE OFFICE

(7) PORTE COCHERE

Figure 6. Ground floor plan of temple (Source: Taylor's University, 2016)

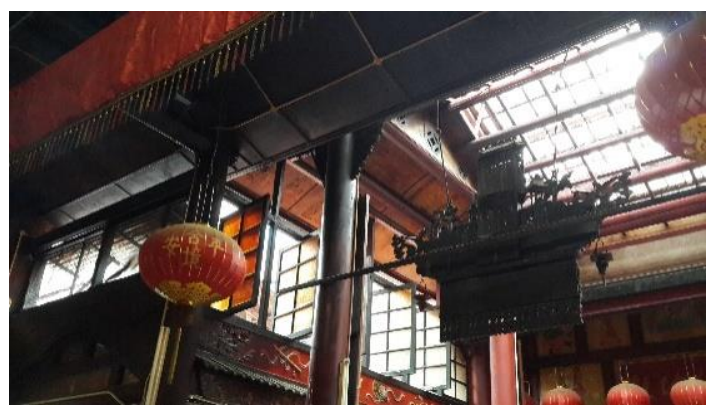

Figure 7. Sheltered Atrium. (Source: Author, 2017)

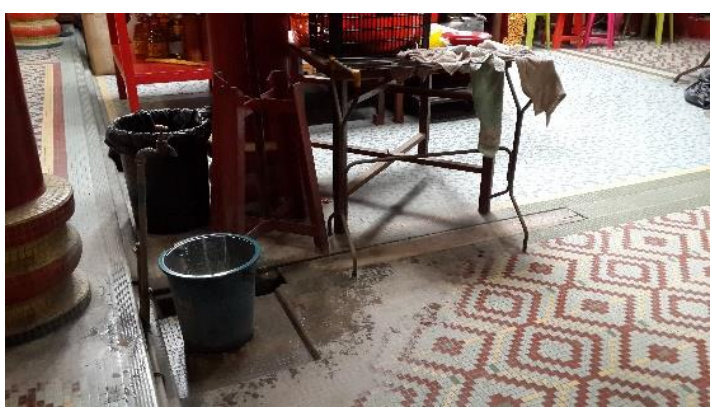

Figure 8: Scupper drain along perimeter of Inner Courtyard. (Source: Author, 2017) 
The Courtyard is smaller than the room and wing mentioned, and hence approximates a light and air well (or sheltered atrium) rather than a courtyard. Further, in traditional Chinese houses the courtyard floor would be depressed in relation to the habitable rooms, partly to control surface water dispersal and partly to give prominence to the parent or living room. Quite often the parent or living room is raised a few steps above the courtyard. Some cognizance is paid to this here: The floor of the Main Prayer Hall is 4 inches $(10 \mathrm{~cm}$.) higher than the Courtyard and adjacent spaces (Fig. 8). The Courtyard floor is differentiated with turquoise mosaic tiles (an inexpensive local variety) which suggests newness and that the courtyard may have been originally lower. Presently, partly covered, scupper drains run along the perimeter of the Courtyard. Note the sump and stand pipe in Fig. 8. Worship and washing, in the mind of the Taoist, at least of this temple, seem equally respectable tasks of life.

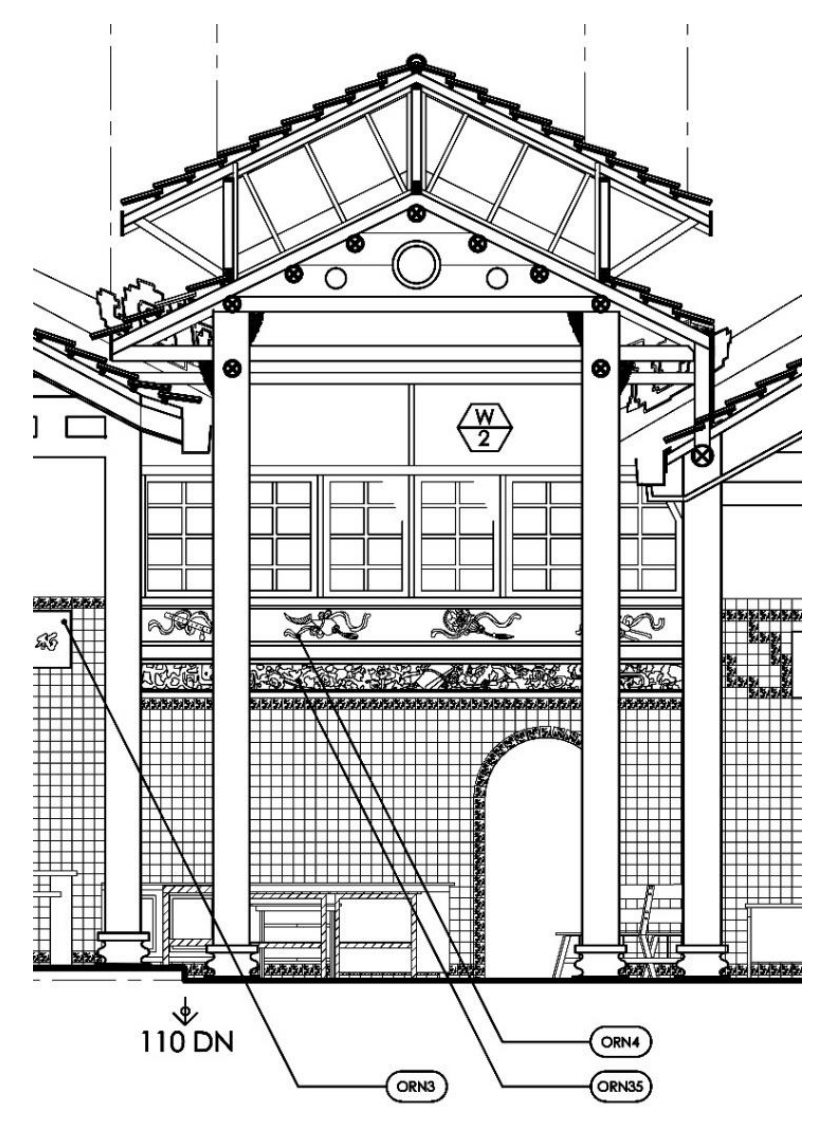

Figure 9. Section across skylight structure. (Source: Taylor's University, 2016).

It appears that practicality of building use was the order of the day. Having diverged architecturally from "genre purity" the task of supporting the courtyard roof took adaptation to a totally new level, resulting in a structural outcome that places the Sin Sze Si Ya in a class of its own. The surrounding structure being unsuitable for support, an independent, four-columned structure with beams, purlins, rafters and battens - all in local, tropical hardwood - was inserted literally into the middle of the temple to boast a double tiered skylight lantern as crown (Fig. 9). The primary structure is clearly Chinese (particularly the log purlins) but the secondary (eaves props and 
window divisions) is not, attesting to a hybrid of design execution. The solution works admirably. It gives the temple an unique architectural identity as it facilitates sustainable lighting and lends the interior an atmosphere that has, literally and psychologically, heaven as a direction.

In contrast, the plethora of tables and altars seems to make the Main Prayer Hall look too small for the main ritual, as tables with religious paraphernalia, and other furniture, extend from where the twin deities are placed prominently at the far centre (Fig. 10) onto approximately half the depth of the Inner Courtyard (Fig. 11). It is unclear at this stage of research (as documentation of the three renovation stages was unavailable for inspection) if this layout was originally intended or that the rituals themselves had undergone change, expanded. The arrangement appears as an afterthought, and although it functions well, this "flexible" use of space, coupled with the skylight structure, alters the interior sense of space - from being that of a courtyard house to that of a large room, albeit a sanctuary. It is not insignificant (in terms of architecture and geomancy) that this central of nine quadrants of the temple is its highest and best-lit point (See sectional drawing, Fig. 5).

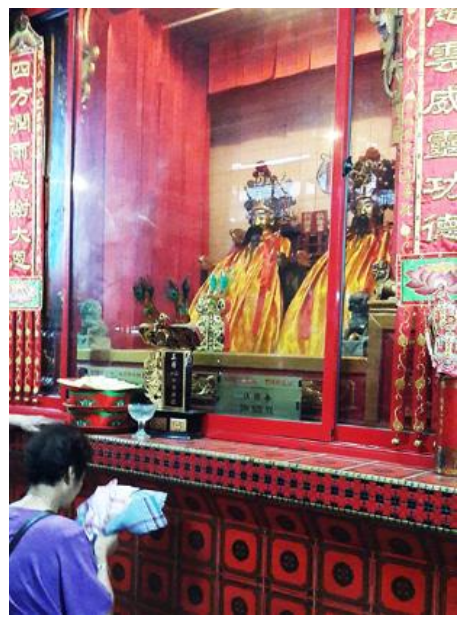

Figure 10. Deities, Sze Si Ya (left) and Sin Si Ya (right), in Main Prayer Hall.

(Source: Author, 2017)

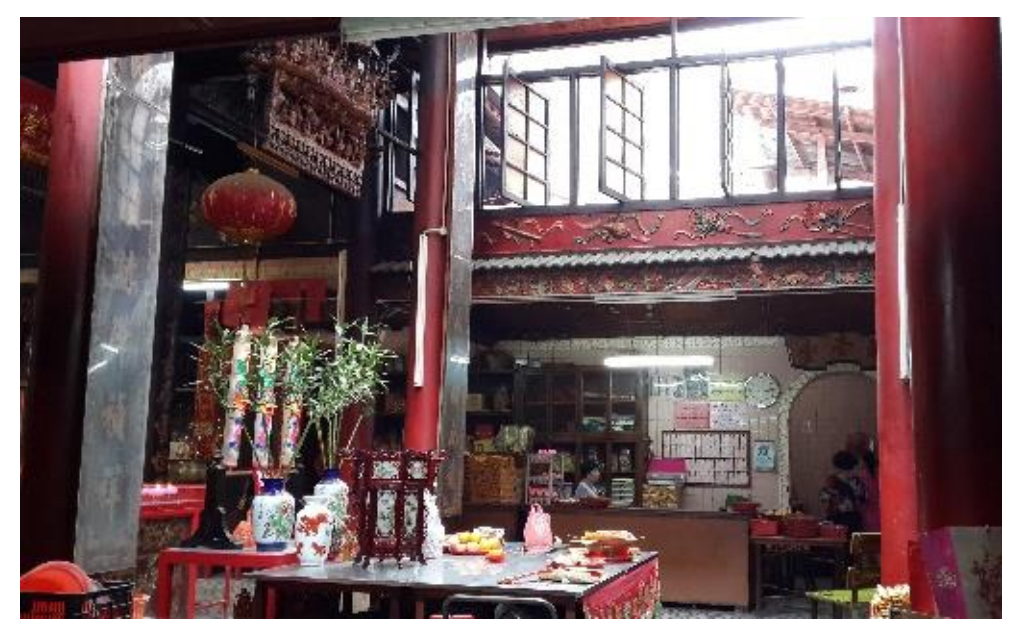

Figure 11. Religious furniture overspills from Main Prayer Hall onto the Inner Courtyard. (Source: Author, 2017)

Further devising is seen in the side wings of the temple where transitional zones are inserted between the middle spatial slice (comprising the Main Prayer Hall, the Inner Courtyard and the Entrance Lobby) and the flanking wing slices (comprising the Ancestral Hall and the Guanyin Hall. Thus, referring to Fig. 12 the line-up of all spaces are, from left to right, the Ancestral Hall of Righteousness and Courage, Utility Zone 1, Main Prayer Hall, Utility Zone 2, and the Guanyin Hall.

The transitional zones serve as toilets, pantries, storage and circulation. All in, the resultant five-slices of space provide a clear functional organization and are also expressed architecturally with thick brick walls separating the spaces. These walls (plastered over and tiled or painted) rise above roof level to form profiled parapet walls. Pragmatically, first floors are inserted into the frontal portions of the flanking and transitional space slices for storage purposes to fully utilize the tall volume of the building. 


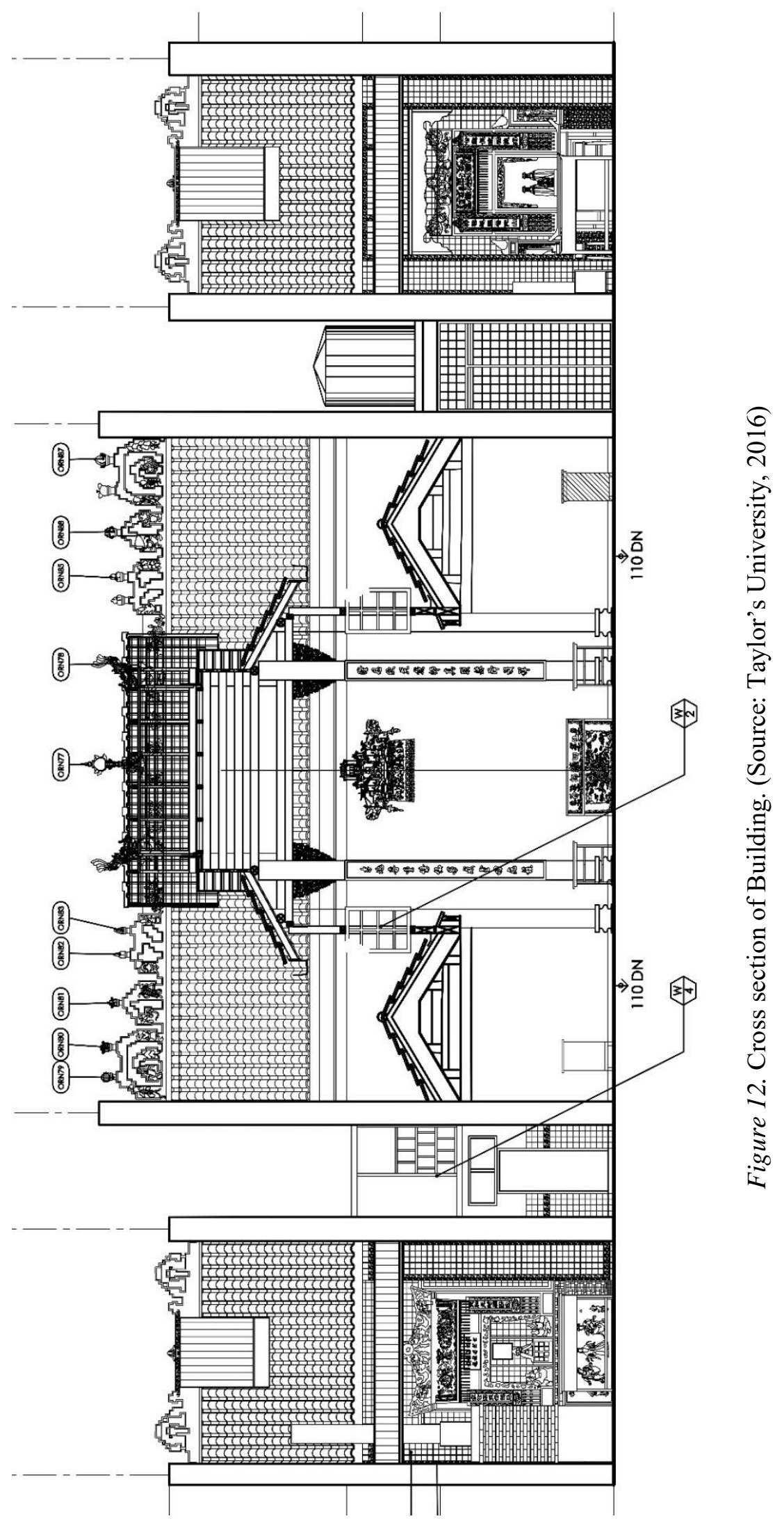


Overall, how the building is fitted together is made clear in an exploded isometric - one form of measured drawing (Fig 13). Walls, ceilings, roofs and openable components when arranged graphically in an exploded isometric drawing give immediate information on the assemblage of the building - a two-dimensional representation of pedagogical experience as much as a scale model is the threedimensional counterpart (Fig. 14).

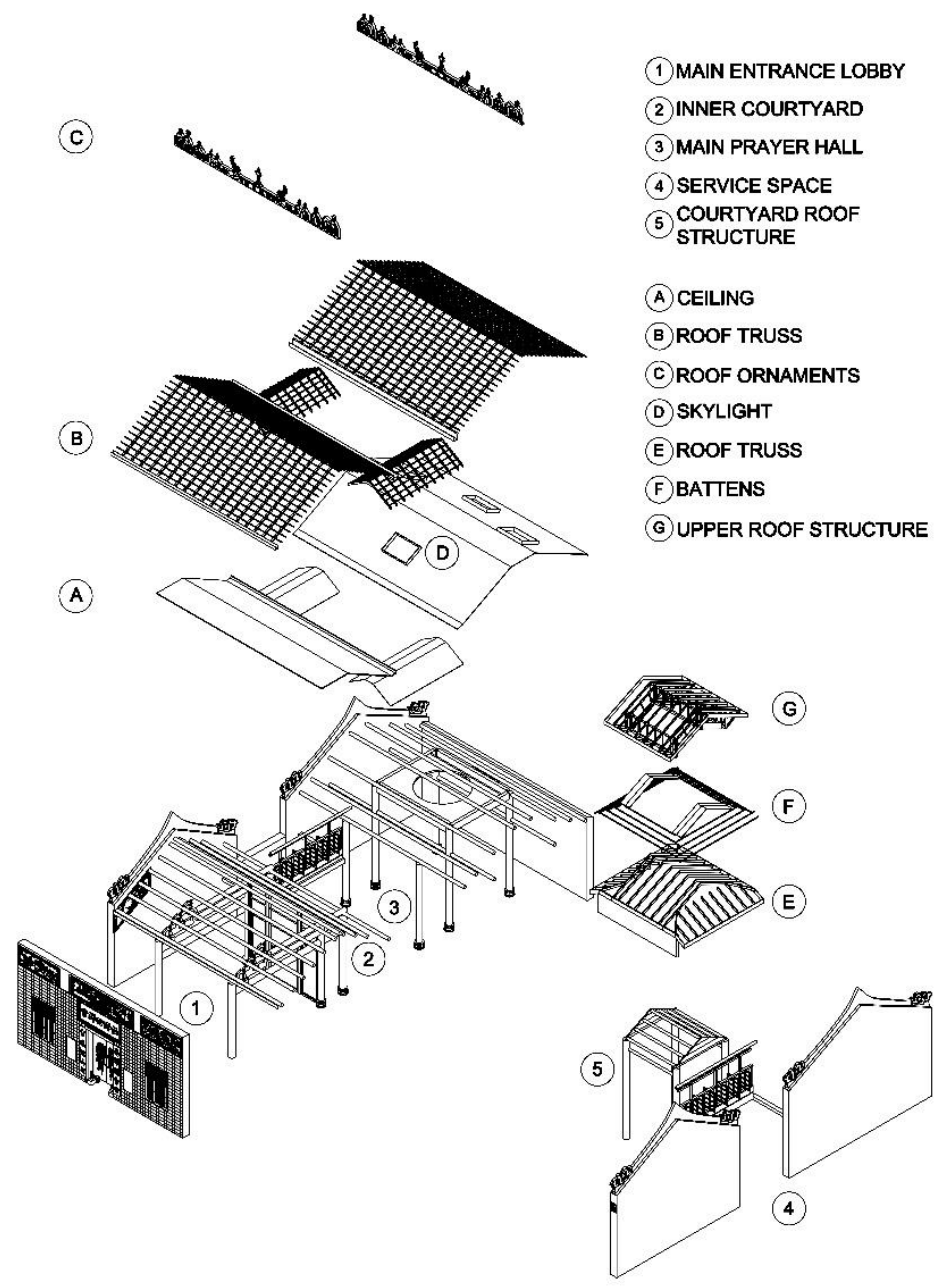

Figure 13. Exploded isometric drawing of central slice of building (Source: Taylor's University, 2016)
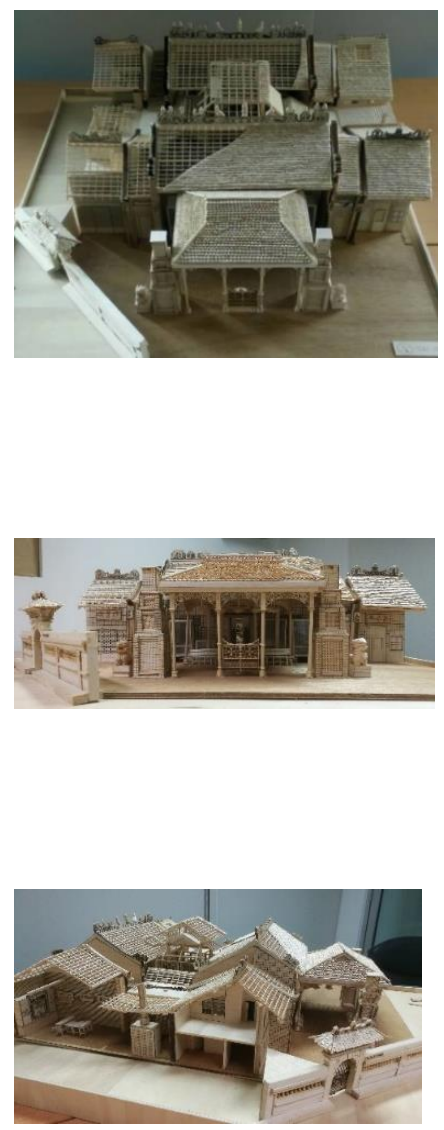

Figure 14. Scale models. (Source: Author, 2016)

In contrast to three dimensional representations elevational drawings form one of the main two-dimensional abstractions of the form of a building. Elevations document how designers and builders imagine a building as a constructible three-dimensional entity. It differs from a realistic photographic capture in one key respect: It does not capture perspective, and, by that token, ascertain how "things line up" (Fig. 15). There are plagues on either side of the main door, and one of these is inscribed with an ode, used as the epigraph of this paper. 


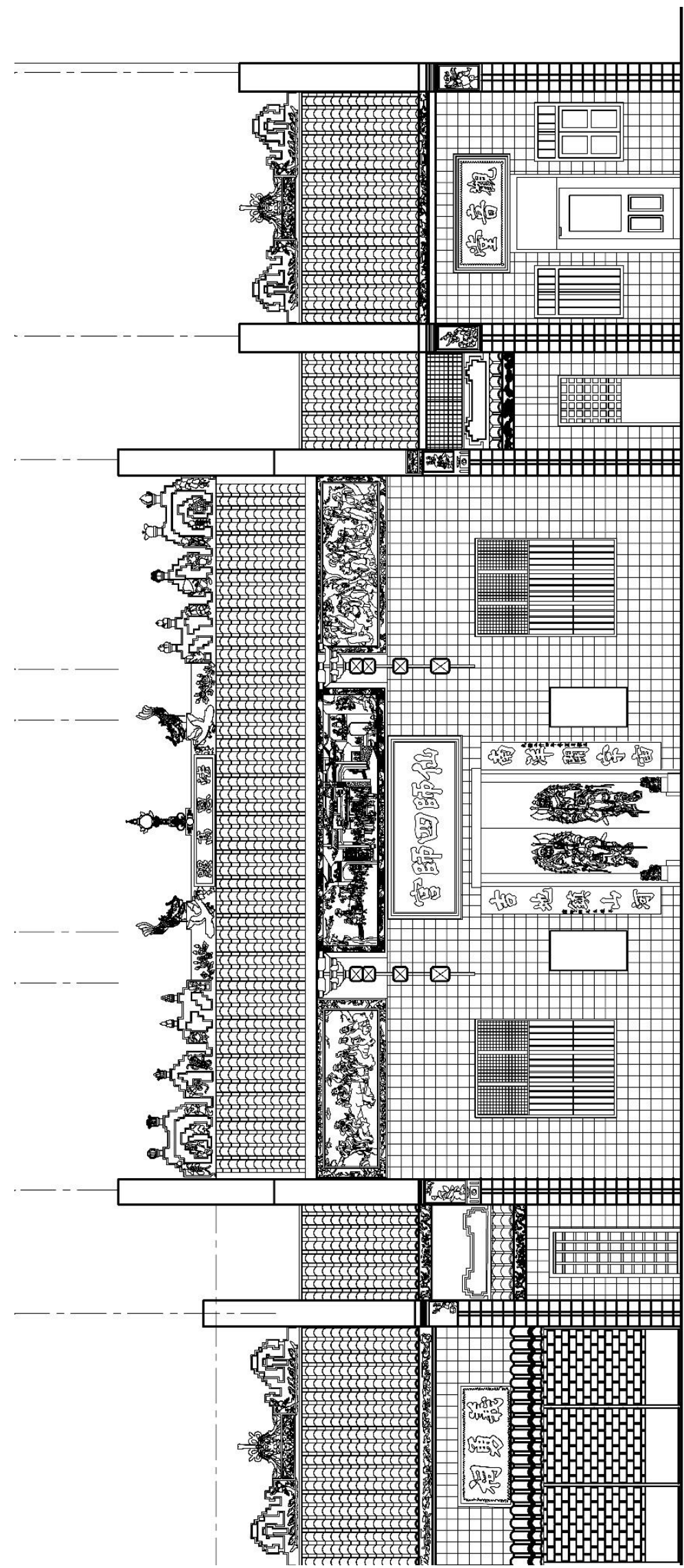

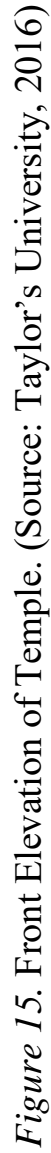




\section{Servicing the Temple}

Not only have the form and space of the generic courtyard house been modified cognitively and through the experience of use over time, the servicing of the interior environment, too, have implanted change. This is most evident in the Main Prayer Hall where galvanized iron ducts intrude into the ceiling space above the main altar, leading to mechanical extract fans in exterior walls (Fig. 16). Together with roof mounted extract fans - some of which are visible on looking up - they serve to dispel smoke from the burning of joss sticks, effigies and "paper money for the afterlife" which (the temple management confirm) was quite unbearable at peak times when natural ventilation was depended upon (Fig. 17).

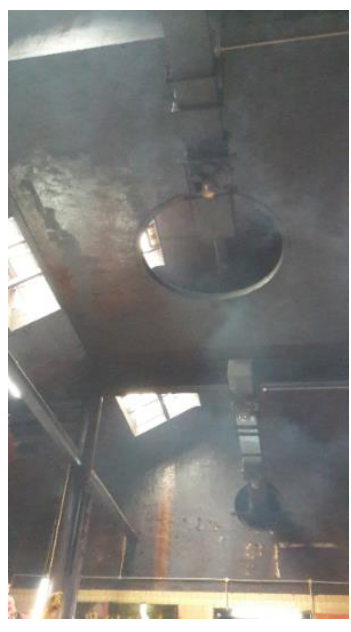

Figure 16. Extract ducts intrude in Main Prayer Hall. (Source: Author, 2017)

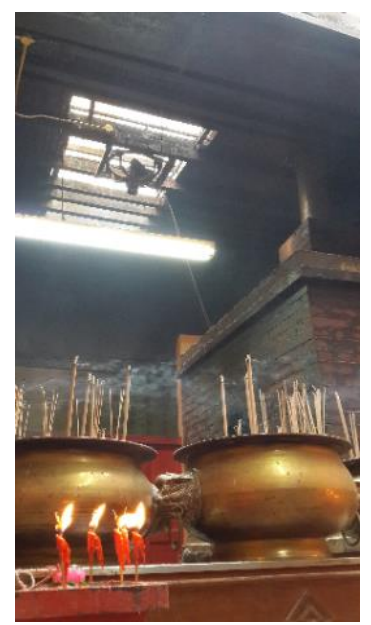

Figure 17. Extract fan above joss stick pots. (Source: Author, 2017)

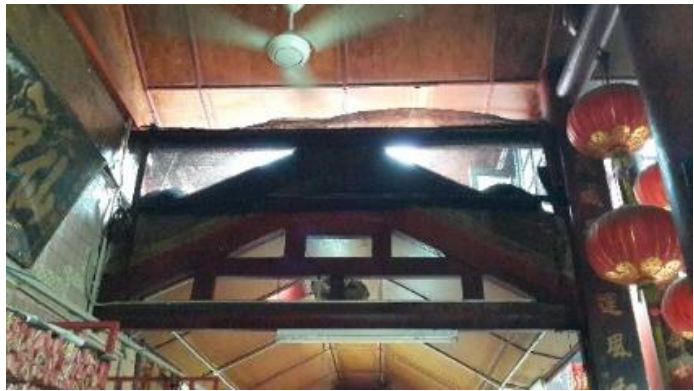

Figure 18. Surface mounted services. (Source: Author, 2017)

Additionally, three-bladed ceiling fans were installed when they came into the market, and bare fluorescent light fittings and electrical conduits run liberally on surfaces of walls and columns, quite indiscreetly, prioritising utility and convenience (Fig. 18). Further, with regard to maintenance, inexpensive glazed tiles are used on walls for ease of cleaning away soot (Fig. 19).

A trained conservationist can think of numerous solutions for (i) hiding these service runs, and (ii) finishing the walls with alternative "period" (even salvaged, heritage) tiles to preserve the architectural character of the interior space. On the other hand, the temple committee, entrusted with management of the building, while aware of aesthetics, appear to have followed a different set of values. It is evident that the task was assigned to non-professionals, and while they cannot be faulted for resorting to very affordable and workable solutions, the architectural quality and user experience could have benefitted appreciably from a better degree of design expertise.

\section{Re-storying}

While the measured drawings delineate, albeit rigidly, the adaptation of the Sin Sze Si Ya to an equatorial climate it is the heritage artefacts housed within speak of social significance. The line-up and arrangement of distinguished persons for taoistic veneration, for example, (Fig. 19) is perhaps the most telling - with Yap Ah Loy as the 
protagonist upfront as a bronze sculpture encased in Perspex. A portrait of him seated ends a line of five other "pioneers of the temple" who were all - coincidentally - born within 9 years of each other, contemporaries of a similar generation. The use of "pioneer" is either a misnomer (if "benefactor" is meant) or a subtle instance of double meaning if "temple" is the operative word (in which case temple may be symbolic of "the land", correlating with the subject in the ode at the entrance to the temple. It is not too fanciful a postulation as four of the six pioneers (other than Chew Yoke and Zhi Ying) have roads named after them in the city. And this interplay between action and recognition in the beginnings of Kuala Lumpur can only be fully understood by considering the plot of the historical narrative. Story, therefore, can communicate meaning as effectively as architecture and its representations.

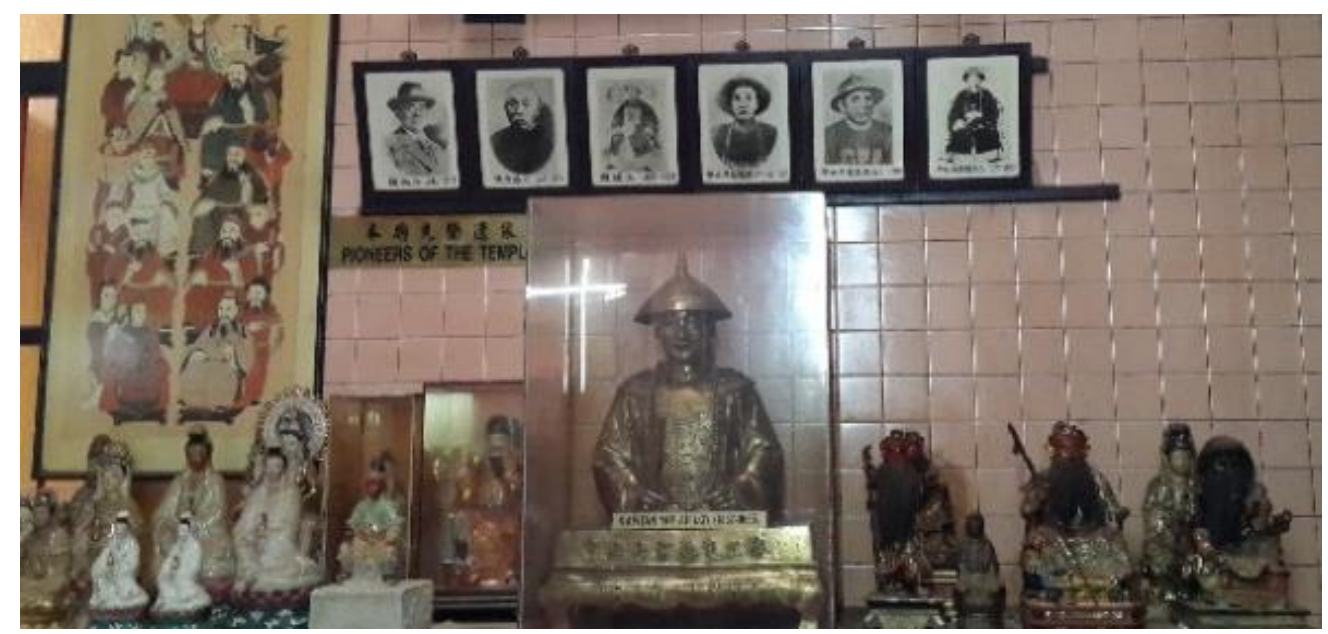

Figure 19. Pioneers of the temple: Front, bust of Yap Ah Loy; rear, photographs (L-R), Loke Yew (1846-1917), Chan Sow Lin (1845-1927), Chew Yoke (1843-1892), Yap Kwan Seng (1846-1901), Yap Zhi Ying (?-1889), and Yap Ah Loy (1837-1885). (Source: Author, 2017)

Yap Ah Loy emigrated from an impoverished, peasant background in Guangdong Province, China, at the age of seventeen in 1854 (Middlebrook, Gullick, \& Gibson-H1ll, 1951) to sail down the South China Sea, round the tip of the Malayan peninsula to build a life and legacy that was to impact a country on the verge of nationhood, before dying at the relatively young age of 48 .

Starting in the ancient town of Malacca, he worked in a tin mine until it closed down, whereupon he continued first in a shop in Kesang, nearby, and later as a cook in Lukut in the neighbouring state of Negeri Sembilan (Fig. 20). All three towns owed their existence to tin mining. By the age of twenty he had saved enough money to commence a pig-trading business. On account of his networking, his business expanded, and he was soon appointed as assistant bodyguard to the Chinese Kapitan of intra-state Sungei Ujong, a man by the name of Shin, and it is this Shin (仙) who would later lend his name to the first character of Sin Sze Si Ya temple (Shin, being the anglicized version of the Cantonese Sin.) The appointment was on the recommendation of Kapitan Shin's personal bodyguard, Liu Ngim Kong. All three hailed from the same district of Hui (Huizhou) in Guangdong, and they were Hakkas. 


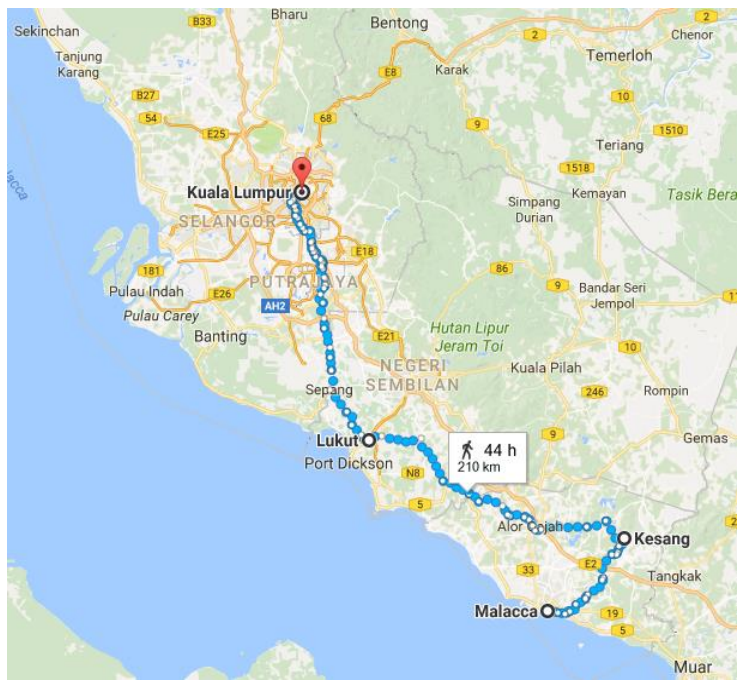

Figure 20. Yap Ah Loy's trajectory from Malacca to Kuala Lumpur via Kesang and Lukut. (Source: Author, 2017)

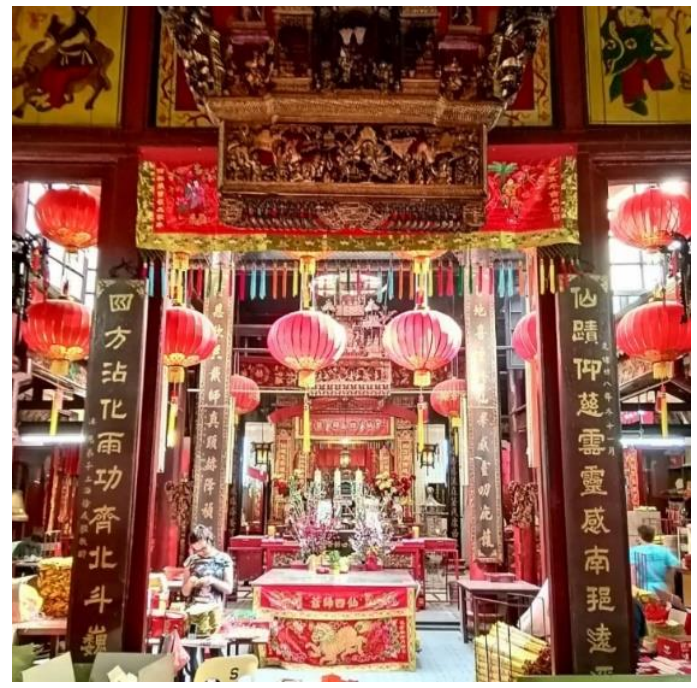

Figure 21. Interior of Temple. (Source: Allen Wei Jie Chin, 2019)

The import of Yap Ah Loy's life experience to the history of Malaya (later, Malaysia) would not rest with mere trading. It would only really begin when entrepreneurship was layered over with civil commotion, for in 1860, when the Malays began to battle the Chinese over tin revenues in this area of Negeri Sembilan, Yap the immigrant businessman joined in with Liu Ngim Kong to fight alongside their employer, Kapitan Shin. They lost. Both wounded, Liu and Yap fled into hiding, while Kapitan Shin, however, met a life changing destiny. He was caught and beheaded. The lives that were changed as a result was not just Shin's. Yap's life - and the lives of the Chinese community into the future - would be steered by the unique events that followed the decapitation. 'According to reports... a miracle took place at his death when white blood, instead of red, flowed from his body' (Carstens, 1988). However sceptical one may be of the historical truth of such an occurrence what is clear is that the oral recounting had profound populist effect to the extent that the affected parties considered deifying Shin, thus birthing a religious ritual which remains to this day. Shin's subordinates built a temple called the Qian Gu Temple in the district of Rasah, in the town of Seremban, to worship their leader whose deification had been validated by the purported miracle (Sin Sze Si Ya Temple Committee, 2009). Yap would later transfer the contents of this shrine to the temple he would build in Kuala Lumpur.

In less than a year from the start of this minor war, Yap Ah Loy (at twenty-four years of age) was offered the post of Kapitan of Sungai Ujong by its principle miner, Yap Ah Shak, who had himself declined the post. Although Yap Ah Loy accepted the position, he resigned a year later to join Liu Ngim Kong who had risen to be the acting Kapitan of Kuala Lumpur - a rough district further north in the state of Selangor where tin-rich plots were being unearthed. While assisting Liu he himself prospered quickly to own two tin mines and a drug store within two years. He married a Chinese from Malacca within this period. 
Sparks that would ignite the larger, Selangor Wars occurred in 1866. There ensued battles over tin rights and revenues for which Malay royalty fought amongst themselves with the Chinese taking sides (Carstens, 1988). Liu Ngim Kong fell ill in 1868 and arranged for Yap to succeed him. Between 1870 and 1873 the Selangor Wars ran its course, in which Yap led the Hui Zhou Hakkas of Kuala Lumpur against the Jiaying Zhou Hakkas of Kancing in the north. In a debacle that saw victory change sides a couple of times Yap was left almost completely resource depleted with his victory. His prime reward was the "Kapitancy" of Kuala Lumpur, conferred by no less than the Sultan of Selangor himself. Yap was then thirty-six years old.

Rebuilding of his devastated assets, which was primarily land and businesses in Kuala Lumpur, was a huge challenge. He would have been bankrupted if not for the sudden doubling of the price of tin in 1878. He then prospered immensely for the next seven years. He died in 1885 , survived by a wife and two sons. His closing years has been described as follows: 'He also not only continued as a major tin magnate, but built roads, invested in various agricultural schemes, and was the first to import a steam pump for use in the Selangor mines. As a philanthropist he built a refuge which offered free food and shelter to the sick and he led in the building of Kuala Lumpur's first Chinese School' (Carstens, 1988). An 1895 map of Kuala Lumpur shows the extent of building on the east bank of the river of mainly commercial buildings. Of these Yap Ah Loy owned 146 shophouses. In terms of physical legacy evident at present, the most publically palpable are a short street named after him (Jalan Yap Ah Loy) and, indisputably, the Sin Sze Si Ya temple nearby. (See Peng \& Ng, 2018, p. 79-81 for maps and discussion on Yap's properties.)

\section{From Myth to Building}

An event that is difficult, if not impossible, to verify on account of the lack of skilled observation and documentation is often as contentious as it is powerful. The fact that sufficient numbers of people were impacted enough emotionally and spiritually is undeniable as the sight of "white blood" issuing forth from a decapitated torso was the impetus and inspiration for a temple to be built to worship the unfortunate hero. Reporting by first hand witnesses of unimaginable events have a tendency to morph in retelling. The temple's official publication (translated for this author by Lee Kai Yung) is discrete enough to acknowledge this tendency as it says: 'The news was spread all over the place and soon become a myth. It was said that (Shin) was always kind and had a heart of Buddha, hence after he was killed he took his place as one of the gods. Ever since then, (Shin) was regarded and looked upon by the people as a god, and a temple was built in order to worship him' (Sin Sze Si Ya Temple Committee, 2009).

Yap Ah Loy never forgot his superior, not since he claimed supernatural direction from Shin's spirit (Sin Sze Si Ya Temple Committee, 2014). Thus after his phenomenal rise in business after only two years in Kuala Lumpur he returned to Qian $\mathrm{Gu}$ in Rasah to "invite" the spirit of Shin to reside in a building in Kuala Lumpur, which was named the Sin Si Ya Temple, "Si Ya" being an honorific meaning "Master." This form of invitation is a Taoist spiritual ceremony still practised to this day. It is reported that Yap Ah Loy thence paid abeyance at the altar of Sin Si Ya day and night. 
Nine years later, at the end of the Selangor Wars, the Chinese community decided to totally rebuild the temple to a level befitting their increased veneration of Sin $\mathrm{Si} \mathrm{Ya}$, and hence Yap gifted a portion of his coconut plantation toward the rear of his residence for the building of the present temple and its adjoining six commercial shophouses (Sin Sze Si Ya Temple Committee, 2014). The 1895 map shows the city lot (circled red) of which the temple property forms a part. The legal boundary of this lot remains to this day. Funded by Yap and the community, the building project commenced in 1873 and was completed in 1875. Sometime toward the end of the Selangor Wars, Yap's commander-in-chief, the fourth sibling from a family surnamed Zhong, passed away to leave a legacy of valour and military leadership. In gratitude Yap made this "fourth Zhong" the joint deity to be housed in the temple. Hence the name Sze (四), meaning "four", was added to form "Sin Sze" in the temple name. The building is therefore literally the temple of Master Sin and Master Sze. The name has remained, but since its opening the temple has undergone three phases of renovations, (i) from 18811883, (ii) in 1938, and (iii) in 1949 to repair the extensive damage inflicted by the Second World War.

\section{Discussion}

While the extended and vehement debate surrounding the passing of Yap's status to Raja Abdullah in the 80's has abated, contenders do not cease to arise. The most recent is the claim that a Mandailing nobleman and merchant of significant economic standing, by the name of Sutan Puasa, deserves the accolade (Lubis, 2018). While the proposition needs to undergo academic review and critique (which is, at this point, scanty) my argument, for the purposes of this paper, takes a tangential route. Subscribers and dissenters have surfaced lightly. Of note, albeit an opinion to a newspaper, is the suggestion that the term, "founder", begs semantic agreement:

'If it refers to 'originator', 'establisher' or as stated by Sharon A. Carstens, as 'the first important person on the scene', the founder of Kuala Lumpur is arguably Hiu Siew (the first Kapitan Cina of Kuala Lumpur)... (who) established a trading post... which as stated by Middlebrook... became known as Kuala Lumpur.

If the term 'founder' refers to 'builder', prime mover' or... 'the preson who expended the most effort in early years to build an develop the city' the founder of Kuala Lumpur is undoubtedly Yap Ah Loy, the third Kapitan Cina of Kuala Lumpur" (Malhi, 2017).

Malhi disagrees that either Sutan Puasa (Lubris' thesis) or Rajah Abdullah (the current, ministry sanctioned founder) deserve the title. I would however suggest that Lubris ought to be given credit for his voluminous scholarship which adds to our knowledge of extents of contribution (in urban development and social structuring terms) that each party - and any party whom might yet emerge - has contributed to the founding of the city, perhaps best defining "founding" as "involved in establishing or originating an institution or organization" (Oxford Living Dictionaries, 2019). It is thus a question of research mapping. 
Nevertheless, the political implications should not escape us. Statuses as labels translate easily into historical markers which have a consolidating impact for communities seeking recognition of their identities and position in a multi ethnic nation. It is apparent that if the status of a member of an ethnic community is heightened in the larger, multi-ethnic society then this sense of importance, with its possible tangible benefits, transmits toward the community. A contested and constructed entity, notwithstanding, it may in fact buttress community identity - which itself is a constructed entity. The status may need to be claimed collectively as a way to "standardize their public image" as a form of "strategic essentialism"; and, perhaps most emphatically (if Yap Ah Loy is part of Chinese legacy at all) "the maintenance of Chinese culture over time can be seen as a strong reification of their moral authority..." (Eide, 2010, p. 76).

Yap Ah Loy may well be a symbol for the Malaysian Chinese community, and if so, employing him astutely as a cultural marker (along with "myths, codes, icons, and sentiments to create the illusion of homogeneity of a group" can fortify a "collective worldview" (of self) (Salih, 1998, quoted by Chong, 2012). This serves proceeding generations for when "these symbols, myths and narratives are passed down as heritage... their centrality to the people's worldview and identity are further reinforced (James, 2007). Passive reactions regarding this challenge could well lead to (further) containment of the Chinese community seeking a more assertive presence in the national consciousness, a participatory reversal at the identity level that corresponds with their physical-spatial containment within confined urban entities such as Chinatown (See Peng and $\mathrm{Ng}, 2018$, for a detailed discussion on this phenomenon). The implicit conviction that much is at stake in ascribing the founder of Kuala Lumpur is understandable.

It may be some time to go yet before nationality overtakes ethnic identity but presently, some writers observe that in Malaysia "it is not sufficient to be Malaysian" one has to have an ethnic identity" (Tan, 2000, p. 464). The Sin Sze Si Ya temple, an inanimate object, may be seen as an aid to focus such intellectual exercises.

\section{Conclusion}

Amidst the cacophony of claims for cultural identity the mute representation of Yap Ah Loy in bronze stares into the space of the spiritual house he built (Fig. 21). As incense smoke pervades the ambience, wafting out the front door, I am made aware of the epigraph as an innocuous, yet ironical, declaration of his community's justification for belonging, as much as it sums up the ethos of the Sin Sze Si Ya. The subtext resounds. In the perception of the temple builders the Chinese diaspora to this country developed the city from "barren land" 2 with warring "native tribes" in "remote areas"2. The description of the earlier-settled Malays is less than complimentary, but the attitude of the newcomers appears benign and conciliatory in their being "determined to bring peace" 3 . Not only did the Chinese succeed in their developmental endeavours, they possessed what can only be described as a noble and far-reaching agenda of countrybuilding. If that were true, as the temple would have us believe, the impetus then for such a purpose - the declared reason why the Sin Si Sze Ya was built - would be one that is shared as an implicit raison d'etre by the Chinese in Malaysia. The epigraph 
continues, hoping that diverse communities can transcend ethnically "territorial barriers"4 to live in harmony - a wish that must surely navigate the difficult terrain between assimilation and integration. Judging by the challenges that contemporary Malaysian Chinese continue to face in regard to their equitable citizenry rights, this wish - nearly one and a half centuries old - is still pertinent.

This paper can only be a modest contribution - a stirring up, so to speak - chiefly in the unearthing of researchable topics embedded within the Sin Sze Si Ya that are framed within the larger debate of representation as heritage and constructed narratives as the given in contestations for cultural identity. The writing process has, nevertheless, revealed areas for future research worth undertaking, and would include (but are not limited to, and in random order) (i) further knowledge disseminated by representations of the temple, other than the measured drawing, (ii) interpretive discourses on the changing status of Yap Ah Loy in the context of the city, nation and ethnic community, (iii) the stages of architectural adaption as the temple evolved over time, (iv) narrative analyses of reflections of Yap's descendants on the meaning of Yap's life, and (v) a translation into English of historic documents of the Yap clan in relation to the life and times of Yap Ah Loy. While the tenor of the epigraph appears to be reconciliatory, at best reading (and a little patronising at worst) its objective seems to be, inarguably, to announce and record rather than to accuse. The socio-political movements of the day, however, may require articulations that are less understated than that evident in this relatively small building. What is clear, certainly, is that - with its obstinate and thriving existence - the Sin Sze Si Ya may be quiet, but it is not silent.

\section{Acknowledgements}

A much abbreviated and significantly different version of this paper (A Temple of the Chinese Diaspora: The Sin Sze Si Ya, Kuala Lumpur) was presented in June, 2017 at the ARCHDESIGN '17/IV International Architectural Design Conference, Istanbul, organized by DAKAM. I am grateful to Taylor's University for supporting the research and funding my participation in the conference. I thank participants at the conference for their comments, and Prof Dr A. Ghafar Ahmad for helpful comments on the first draft of this paper. Errors and omissions, if any, are naturally all mine.

\section{References}

Akboy, S. (July 02, 2017). Crafting the Architectural Measured Drawings. The Plan Journal, 2, 1, 39-61.

Carstens, S. A. (1988). From myth to history: Yap Ah Loy and the heroic past of Chinese Malaysians. Journal of Southeast Asian Studies. 19(02):185-208.

Chong, J. W. (April 01, 2012). "Mine, Yours or Ours?": The Indonesia-Malaysia Disputes over Shared Cultural Heritage. Sojourn: Journal of Social Issues in Southeast Asia, 27, 1, 1-53.

Chong, J. W. (January 01, 2012). “Mine, Yours or Ours?”: The Indonesia-Malaysia Disputes over Shared Cultural Heritage. Journal of Social Issues in Southeast Asia, 27, 1, 1. 
Eide, E. (December 09, 2010). Strategic essentialism and ethnification: Hand in Glove?. Nordicom Review, 31, 2, 63-78.

Geertz, C., \& Darnton, R. (2017). The interpretation of cultures. New York: Basic Books.

Graham, B. (May 01, 2002). Heritage as Knowledge: Capital or Culture?. Urban Studies, 39, 1003-1017.

Gullick, J. M. (1988). Kuala Lumpur (1880-1895): A city in the making. Petaling Jaya: Pelanduk.

Gullick, J. M. (2000). A history of Kuala Lumpur 1856-1939. Kuala Lumpur: MBRAS.

Hall, S. (Ed.) (1997) Representation: Cultural Representations and Signifying Practices. London: Sage/Open University.

In Denzin, N. K., \& In Lincoln, Y. S. (2018). The SAGE handbook of qualitative research.

James, Peter C. "Human Rights, Cultural Heritage Conservation and Cultural Tourism - Conflict or Collaboration?" Conference by the International Council on Monuments and Sites (ICOMOS), "Heritage, Identity, Cultural Heritage, Cultural Diversity and Human Rights: Professional Challenges, Cairns, Australia, 19-21 July 2007".

Kovach, M (2018). Doing Indigenous Methodologies. In Denzin, N. K., \& In Lincoln, Y. S. (2018). The Sage handbook of qualitative research

Liu Dunzhun, ed. Zhongguo gudai jianzhu shi. [Beijing: Zhongguo gongyue chubanshe, 1984], p. 12. https://depts.washington.edu/chinaciv/tg/thome.pdf. (Accessed on 2017.01.19)

Lowenthal, D. (1998). The heritage crusade and the spoils of history. New York: Cambridge University Press.

Lowenthal, D. (2016). The past is a foreign country - revisited

Lubis, A.-R. (2018). Sutan Puasa: Founder of Kuala Lumpur.

Malhi, R. S. (2017). The history of Kuala Lumpur's founding is not as clear cut as some think. Star Online, May 2017. (https://www.thestar.com.my/metro/views/2017/05/05/setting-the-recordstraight-the-history-of-kuala-lumpurs-founding-is-not-as-clear-cut-as-somethink/, accessed 30 March 2019)

Middlebrook, S. M., Gullıck, J. M., \& Gibson-Hill, C. A. (1951). Yap Ah Loy (18371885). Journal of the Malayan Branch of the Royal Asiatic Society. 24, 1-127.

Mohamed, S. M. A. (January 01, 1998). Other Identities: Politics of Sudanese Discursive Narratives. Identities Newark-, 5, 1, 5-32.

Oxford Living Dictionaries, https://en.oxforddictionaries.com/definition/founding (accessed 1 May 2019).

Peng, N. F., \& Ng, I. A. S. (April 01, 2018). Old Market Square as a Container of Diasporic Meaning in Chinese Kuala Lumpur. Millennial Asia, 9, 1, 66-92.

Pillai, V. (2018). Academic calls for recognition of Sutan Puasa as KL's founder, (https://www.thestar.com.my/metro/community/2017/04/24/sharing-theirthoughts-on-kls-history-historian-architect-and-veteran-radio-announcer-givetheir-vie/, accessed March 30, 2019.)

Salih, M. A. Mohamed. (January 01, 1998). Other Identities: Politics of Sudanese Discursive Narratives. Identities Newark-, 5, 1, 5-32.

Sathian, M. R., \& Ngeow, Y. M. (January 01, 2014). Essentialising Ethnic and State Identities: Strategic Adaptations of Ethnic Chinese in Kelantan, Malaysia. Asian Studies Review, 38, 3, 385-402.

Sin Sze Si Ya Temple Committee. (2009). The Sin Sze Si Ya Temple, Kuala Lumpur. 
Sin Sze Si Ya Temple Committee. (2014). Kuala Lumpur Sin Sze Si Ya Temple.

Star Online, (2017). Sharing their thoughts on KL's history

Tan, C.-B. (January 01, 2000). Ethnic identities and national identities: some examples from Malaysia. Identities, 6, 441-480.

\section{Credits}

Figure 5: Drawing delineated by Jason Lim \& Mohd Azzam bin Abdul Aziz.

Figure 6: Drawing delineated by Mark Eng Shang.

Figure 9: Drawing delineated by Mohd Azzam bin Abdul Aziz.

Figure 12: Drawing delineated by Mohd Azzam bin Abdul Aziz.

Figure 13: Drawing delineated by Mark Eng Shang.

Figure 15: Drawing delineated by Tang Ju Yi, Victor Heng Wei, Jiahui Ong \& Liew Jin

The measured drawing project with model making was taught and supervised by Dr Sucharita Srirangam \& Ar Ian Aik-Soon Ng in 2016.

Line weight for all delineated drawings was balanced by Louis Sia Kee Leong in 2019. 